\title{
Motivação para Aprendizagem no Curso de Ciências Contábeis: Um Estudo Comparativo entre Alunos da Modalidade Presencial e a Distância, referente à Disciplina de Controladoria ${ }^{1}$
}

\author{
Motivation for Learning in Higher Course of Accounting Sciences: A \\ Comparative Study Between Students of Present Mode and \\ Students of Distance Mode, as to the Discipline of Controllership
}

\author{
Motivación para Aprendizaje en el Curso de Contabilidad: Un \\ Estudio Comparativo entre Estudiantes del Curso Presencial y Del \\ Curso en Modo a Distancia, en la Disciplina de Controle de \\ Gestión
}

\author{
Carlos Roberto Souza Carmo \\ Professor Assistente da Universidade Federal de Uberlândia-UFU \\ Universidade Federal de Uberlândia, Faculdade de Ciências Contábeis. \\ Endereço: Av. João Naves de Ávila, 2121 Bloco F - Sala 1F 215 \\ Santa Mônica, CEP: 38.400-902 - Uberlandia, MG - Brasil \\ e-mail: carlosjj2004@hotmail.com
}

\section{RESUMO}

O presente estudo teve por objetivo geral analisar, comparativamente, como fatores relacionados à idade, ao gênero, à existência de experiência profissional na área contábil, o tempo relativo àquela experiência e o período/etapa em que o aluno, da modalidade presencial e a distância, se encontra no curso Ciências Contábeis poderiam constituir-se em direcionadores da sua motivação para cursar a disciplina de Controladoria. A partir da aplicação da análise de regressão linear, pelo método stepwise, foram identificadas duas modelagens matemáticas explicativas da motivação daqueles discentes. Entre outras evidências, foi observado que, tanto nos alunos do curso presencial quanto os alunos do curso a distância, a idade foi o principal determinante da motivação para cursar a disciplina de Controladoria. Também, foi observado que fatores relacionados à experiência profissional dos discentes integrantes da amostra dessa pesquisa exercem influências distintas em relação à modalidade de ensino frequentada por cada um dos dois grupos investigados. No caso dos alunos do curso presencial, o tempo de experiência profissional na área contábil tem um comportamento inverso à motivação. Dentre os alunos do curso a distância, o tempo de experiência profissional na área contábil não foi considerado estatisticamente significativo, porém, a simples existência de algum tipo de experiência profissional naquela área constituiu-se em um fator determinante da sua motivação para cursar a disciplina de Controladoria, independentemente do tempo dessa experiência.

Palavras-chave: Motivação. Aprendizagem. Métodos quantitativos aplicados.

\footnotetext{
${ }^{1}$ Artigo recebido em 21.08.2013. Revisado pelos pares em 20.05.2014 (blind review). Ajustado e Aceito para publicação em 01.07.2014. Recomendado para publicação por José Ribamar Marques de Carvalho (Editor Científico). Publicado em 15.08.2014. Organização responsável UACC/CCJS/UFCG.
} 


\begin{abstract}
The present study was aimed at analyzing, comparatively, general factors related to age, gender, existence of professional experience in accounting, time and experience relative to that period/stage in which the student, the classroom mode and the distance mode, is in the course Accounting could form themselves into drivers of their motivation to take the discipline of Controllership. From the application of linear regression analysis, stepwise, two explanatory mathematical modeling of the motivation of those students were identified. Among other evidence, it was noted that both students of present mode as students of distance mode, age was the main determinant of motivation to take the course the discipline of Controllership. Was also observed that factors related to the experience of the students included in the sample of this study exert distinct influences in relation to the type of education attended by each of the two groups investigated. For students of present mode, the length of professional experience in the accounting field has an inverse behavior to motivation. Among the students of the distance mode, the length of professional experience in accounting was not considered statistically significant, however, the mere existence of some kind of professional experience in that area constituted a determining factor in their motivation to take the course the discipline of Controllership, regardless of the time of this experience.
\end{abstract}

Keywords: Motivation. Learning. Quantitative methods applied.

\title{
RESUMEN
}

El presente estudio tuvo como objetivo analizar, comparativamente, la relación del edad, el género, la existencia de una experiencia profesional en contabilidad, el tiempo en relación a la experiencia y el período/fase en que el estudiante, em la modalidad presencial y el modo a distancia, se encuentra en el curso de contabilidad podrían constituirse en factores de su motivación para cursar la disciplina de Controle de Gestión. A partir de la aplicación del análisis de regresión lineal, paso a paso, se identificaron dos modelos matemáticos explicativos de la motivación de los estudiantes. Entre otros factores, se observó que, tanto los estudiantes del curso presencial como lós estudiantes del curso a distancia, la edad es el principal factor determinante de la motivación para tomar el curso de Controle de Gestión. Se observó también que los factores relacionados con la experiencia de los estudiantes en la muestra de este estudio ejercen influencias distintas en relación con el tipo de curso que asistieron a cada uno de los dos grupos investigados. Para los estudiantes del curso presencial, la duración de la experiencia profesional en el campo de la contabilidad tiene un comportamiento inverso a la motivación. Entre los estudiantes Del modo a distancia, la duración de la experiencia profesional en contabilidad no se consideró estadísticamente significativo, sin embargo, la mera existencia de algún tipo de experiencia profesional en este ámbito de la contabilidad constituye un factor determinante en su motivación para tomar el curso Controle de Gestión, independientemente de la duración de esta experiencia.

Palabras clave: Motivación. Aprendizaje. Métodos cuantitativos aplicados.

\section{INTRODUÇÃO}

A Controladoria surgiu a partir do início do século XX, quando a expansão do número de empresas geradas pela Revolução Industrial fez com que as organizações começassem a se fundir originando grandes entidades organizadas sob a forma de departamentos com controle centralizado (SIQUEIRA; SOLTELINHO, 2001).

Ao levar em conta que as empresas em geral estão sujeitas a mudanças, tanto no seu ambiente interno quanto no externo, sendo elas relacionadas em grande parte à competitividade, inovação tecnológica, custos, entre outros fatores, a informação produzida a partir dos controles gerenciais passou a ter maior relevância com o aumento da competitividade econômica em nível mundial (SOUZA; LISBOA; ROCHA, 2003; AMARAL; RODRIGUES, 2006).

Desde o seu surgimento até os dias atuais, a Controladoria ganhou força nas organizações, sendo que, segundo Beuren (2002), o seu desenvolvimento pode ser 
atribuído a três fatores básicos: verticalização das organizações, diversificação produtiva e expansão das organizações.

Percebe-se, então, a relevância da Controladoria no contexto econômico atual. Nesse sentido, para atender às necessidades do mercado, no que se refere à demanda por profissionais desta área, as instituições de ensino superior (IES) ofertantes do curso de Bacharelado em Ciências Contábeis exercem um papel relevante na formação desse tipo de profissional, no caso, o Controller.

A despeito da importância do ensino da Controladoria nos cursos de Ciências Contábeis, Pires (2004) afirma que o ensino superior brasileiro vem sofrendo uma série de mudanças que ainda não foram bem absorvidas pelas IES em geral, com especial destaque para o aumento da oferta e da demanda por vagas e, ainda, o crescente número de instituições particulares, entre outros fatores. Pires (2004) ainda salienta outros fatores relacionados ao surgimento de novos tipos de cursos superiores e novas modalidades de ensino, por exemplo, os cursos sequenciais (nível de graduação), os mestrados profissionais (nível de pós-graduação) e a educação à distância (EAD).

Nesse contexto, parece razoável ponderar que a realização de estudos voltados para o processo de aprendizagem dos alunos do ensino superior pode contribuir para a melhoria na gestão das IES ofertantes dos cursos de Bacharelado em Ciências Contábeis, no que se refere à orientação de políticas educacionais, e, ainda, provocar a reflexão crítica por parte dos docentes desses cursos acerca das práticas de ensino por eles adotadas no processo de formação superior dos respectivos alunos.

Dentre as possíveis e inúmeras temáticas e abordagens de estudos acerca da aprendizagem em nível superior, destaca-se a pesquisa voltada para o diagnóstico de fatores determinantes da motivação discente para aprendizagem, uma vez que, investigações dessa natureza podem constituir-se em uma fonte de explicação para o fato de alguns estudantes aproveitarem melhor sua passagem pela escola, desenvolvendo-se potencialmente, enquanto outros se apresentam desinteressados e passivos (GARRIDO, 1990).

De uma forma geral, estudos voltados para a identificação e à compreensão de fatores que possam influenciar a motivação discente para a aprendizagem em geral, e, no caso deste trabalho, algumas disciplinas específicas do curso de Ciências Contábeis, podem oferecer subsídios capazes de orientar não só a prática docente, mas, também, o dimensionamento curricular (MOREIRA, 1998), tudo isso no intuito de aprimorar o processo de ensino e aprendizagem.

Nesse sentido, o presente estudo foi conduzido a partir do seguinte problema de pesquisa: como fatores relacionados à idade, ao gênero, à existência de experiência profissional na área contábil, o tempo relativo àquela experiência e o período/etapa em que o aluno se encontra no curso Ciências Contábeis, tanto na modalidade presencial quanto a distância, podem constituir-se em direcionadores da sua motivação para cursar a disciplina de Controladoria? 
Para responder ao questionamento direcionador desse estudo científico de caráter empírico-quantitativo, inicialmente, foi realizado o embasamento teórico a partir do qual foi elaborada a segunda seção deste artigo. Na sequência, foi criado e testado o instrumento de coleta de dados, procedida a sua aplicação aos alunos integrantes da amostra desta pesquisa, e, ainda, identificado o método de análise capaz de permitir responder ao questionamento direcionador desta investigação, originando-se assim a seção três deste trabalho. Na terceira fase da investigação, foi realizada a análise dos dados, a respectiva interpretação e relatados os principais resultados, sendo que, toda essa etapa encontra-se detalhada na seção quatro deste artigo. Ao final, na seção cinco deste estudo, foi realizada a apresentação das considerações finais acerca de todo este trabalho de investigação científica.

\section{FUNDAMENTAÇÃO TEÓRICA}

Ao levar em conta os problemas inerentes à aprendizagem, com ênfase ao comportamento dos discentes, as instituições de ensino, professores e outros profissionais da educação devem considerar os aspectos motivacionais, pois, conforme observam Pajares e Shunck (2001), alunos desmotivados tendem a se comprometer menos com as atividades escolares, o que inviabiliza o seu desenvolvimento acadêmico e, por consequência, sua futura atuação profissional, entre outros aspectos.

Convigton (2004) observa que, na maioria das vezes, os alunos atribuem sua falta de motivação aos professores e à escola em geral, já os professores, também em grande parte, responsabilizam os alunos por suas dificuldades motivacionais alegando que cabe exclusivamente ao aluno a busca pelo conhecimento e o interesse pela aprendizagem. Diante desse quadro, Convigton (2004) afirma que a compreensão das variáveis que podem influenciar a motivação discente pode permitir compreender a natureza de posicionamentos tão distintos entre alunos e professores, e, ainda, os motivos que levam certos alunos a se desenvolverem mais que outros ao longo de sua trajetória no ensino.

Contudo, o estudo da motivação no âmbito escolar não é tarefa das mais fáceis, pois, conforme observa Bzuneck (2005), a motivação diz respeito a um construto amplo e complexo, uma vez que está relacionada a orientações internas e multideterminadas, e, por isso, permite que o tema seja abordado sob várias perspectivas, no que se refere a investigações nessa área temática (MURPHY; ALEXANDER, 2000; PINTRICH, 2003; COVINGTON, 2004). Diante da multiplicidade de abordagens referentes à motivação para aprendizagem discente, Buzneck (2004) observa que, embora fosse desejável, ainda não é possível contar com uma teoria geral e definida acerca da motivação humana em geral, tampouco da motivação do aluno para aprendizagem.

Segundo Buzneck (2004) a motivação diz respeito à força que move o indivíduo fazendo com que ele entre ação de forma a impulsioná-lo a um objetivo, 
podendo ser entendida tecnicamente como um conjunto de fatores psicológicos de origem fisiológica, intelectual e afetiva capazes de determinar conjuntamente a ação e a conduta de um indivíduo. Murray (1986, p. 20) afirma que a motivação representa "[...] um fator interno que dá início, dirige e integra o comportamento de uma pessoa." Segundo Pfromm (1987), a motivação é o sentimento que desperta o organismo do ser humano e dirige suas ações no intuito de atingir uma meta estabelecida. Não muito diferente das definições já apresentadas, Garrido (1990) afirma que motivação é um processo psicológico que tem origem no interior do indivíduo e que é capaz de impulsioná-lo a uma ação.

Ao considerar que a motivação exerce um papel significativo no direcionamento das ações do dia a dia do ser humano em geral, parece razoável admitir que ela não poderia estar ausente no ambiente acadêmico. Nesse sentido, Siqueira e Wechsler (2006) afirmam que o aluno motivado tende a se envolver mais com as atividades inerentes ao processo de aprendizagem apresentando um melhor aproveitamento dos seus estudos. Nessa mesma linha de raciocínio, Covington (2004) destaca que somente o aluno motivado assume sua parcela de responsabilidade no processo de aprendizagem.

Valente (2001, p.71) afirma que "motivar ou produzir motivos significa predispor a pessoa para a aprendizagem", ou seja, o aluno motivado tende a buscar e a dar continuidade ao seu processo de aprendizagem. Guimarães e Boruchovitch (2004) corroboram o ponto de vista de Valente (2001) e acrescentam que somente o aluno motivado procurará desenvolver habilidades para a compreensão e domínio de conteúdos a partir de novas habilidades e estratégias de aprendizagem.

Acerca das variáveis que podem influenciar a motivação para aprendizagem, Stipek (1998) afirma que ela tende a apresentar um comportamento inverso aos níveis de estudo, isto é, quanto mais avançadas as etapas de um curso, mais complexos e profundos tendem a ser os problemas relacionados à falta de motivação, sendo que, a intensidade desse fenômeno pode variar de disciplina para disciplina em um mesmo curso.

Essa última constatação de Stipek (1998), acerca da variação dos níveis motivacionais em relação às disciplinas de um mesmo curso, é corroborada por Jacobs e Newstead (2000) que, ao estudarem o comportamento dos alunos do curso de psicologia de uma universidade no sul da Inglaterra, constataram que a motivação dos discentes apresentava variação de uma disciplina para outra de acordo com a sua percepção sobre a importância da disciplina, suas habilidades e/ou experiências pessoais.

Especificamente em relação aos alunos do curso de Ciências Contábeis, Mendes (2000) afirma que a falta de motivação do aluno em relação às suas perspectivas profissionais pode contribuir para os baixos níveis de aprendizado no curso, o que dificulta a compreensão da motivação daqueles alunos. Por outro lado, Mendes (2000) também observa que a predisposição para aprendizagem não 
depende somente de escolas bem equipadas e bons professores, mas também, da motivação dos discentes em relação ao próprio curso.

Buscando analisar a forma pela qual os estudantes de Contabilidade construíam seu aprendizado, Brown (2005) constatou que fatores relacionados gênero, maturidade acadêmica, experiência profissional eram variáveis determinantes da forma pela qual os estudantes direcionavam sua aprendizagem ao longo do curso analisado.

Ao realizar uma análise comparativa entre alunos de IES públicas e privadas nos cursos de Ciências Contábeis de três regiões da Bahia, Lopes, Pinheiro e Silva (2013) constaram que não existiam diferenças significativas entre os níveis motivacionais dos alunos desses dois tipos IES, porém, em relação aos possíveis determinantes da motivação constatada, foram percebidas diferenças estatisticamente significativas em relação ao gênero, estágio/etapa no curso e idade dos alunos de uma mesma IES.

Oliveira et al (2010) realizaram uma investigação com objetivo de identificar qual o nível de motivação predominante entre os alunos do curso de Ciências Contábeis da Universidade Estadual de Montes Claros. Entre outras evidências, Oliveira et al (2010) observaram que os alunos pesquisados apresentavam maiores níveis de motivacionais nos períodos iniciais do curso e, a medida que avançavam nas séries, esses níveis motivacionais iam decrescendo, corroborando assim os achados de Jacobs e Newstead (2000). A despeito da semelhança de resultados, em ambos os estudos não foi identificada qual a razão para a ocorrência desse fenômeno, pois, também em ambas as pesquisas, não se realizou a investigação dos determinantes daqueles tipos/níveis motivacionais, ou seja, apenas a sua identificação.

A despeito dos estudos já realizados, observa-se a ausência de consenso e de uma teoria geral sobre como se processa a motivação dos alunos para aprendizagem (MURPHY; ALEXANDER, 2000; PINTRICH, 2003; COVINGTON, 2004; BZUNECK, 2004), diante disso, o presente estudo justifica-se enquanto possível contribuição para debate relacionado ao assunto em questão.

\section{MÉTODO DE PESQUISA}

Inicialmente, foi elaborado um questionário para a coleta de dados. A primeira parte desse instrumento de coleta teve por objetivo obter dados que permitissem a caracterização do perfil dos respondentes. Na segunda parte do questionário, foi solicitado ao aluno que atribuísse uma nota de 0 (zero) a 10 (dez) de maneira que, a partir dessa nota, ele indicasse o quanto se sentia motivado a cursar a disciplina de Controladoria do curso que estava frequentando, conforme pode ser constatado a partir da análise do Apêndice 1 deste artigo.

Antes de se iniciar a coleta de dados propriamente dita, foi realizado um préteste com 10 alunos do curso de Ciências Contábeis de uma IES diferente daquela em 
foi realizada a presente pesquisa. A escolha de uma IES diferente para realização do pré-teste ocorreu como um meio de se evitar que os alunos integrantes da amostra desta pesquisa formassem algum tipo de pré-conceito acerca do processo de coleta de dados propriamente dito. As opiniões, críticas e sugestões dos alunos que contribuíram com pré-teste serviram de base para a finalização do instrumento efetivamente utilizado nessa investigação.

Após a validação final do instrumento de coleta, foi realizada a coleta dos dados propriamente dita, a partir da aplicação do referido questionário. Esse processo foi realizado ao longo dos meses de agosto e setembro de 2013 e foram obtidas informações referentes a 159 respondentes que passaram a integrar a amostra dessa pesquisa, cujo perfil está resumindo na Tabela 1. Os alunos entrevistados pertencem ao curso de Ciências Contábeis de uma IES privada da cidade de Uberaba-MG, tanto da modalidade presencial (87 alunos) quanto a distância (72 alunos).

Tabela 1 - Perfil da amostra de pesquisa

\begin{tabular}{l|r|r|r}
\hline Categorias & $\begin{array}{c}\text { Dados Gerais } \\
\text { do Curso }\end{array}$ & $\begin{array}{c}\text { Modalidade } \\
\text { Presencial }\end{array}$ & $\begin{array}{c}\text { Modalidade } \\
\text { a Distância }\end{array}$ \\
\hline Quantidade total de alunos & 159 & 87 & 72 \\
\hline Quantidade total de alunos do gênero feminino & 107 & 57 & 51 \\
\hline Quantidade total de alunos do gênero masculino & 51 & 30 & 21 \\
\hline Período - semestre do curso (média) & 4 & 5 & 3 \\
\hline Idade - em anos(média) & 27 & 24 & 30 \\
\hline Tempo de experiência profissional - em anos (média) & 5 & 3 & 7 \\
\hline
\end{tabular}

Fonte: elaborada com base nos dados da pesquisa.

O conjunto de dados representativo da motivação dos respondentes para cursar a disciplina de Controladoria, ou seja, as notas de 0 a 10 (zero a dez), foi considerado como variável de estudo, conforme descrição apresentada no item " $\mathrm{i}$ " do Quadro 1. Já as informações referentes à idade, gênero, experiência profissional e período em que se encontravam naquele curso superior foram consideradas como possíveis variáveis explicativas do grau de motivação dos alunos cujas respostas integraram a amostra desta pesquisa, conforme detalhado pelos itens "ii" até "vi" descritos, também, no Quadro 1.

Quadro 1 - Descrição das variáveis utilizadas no estudo

\begin{tabular}{|l|l|l|l|l|}
\hline \multicolumn{2}{|l|}{ Identificação no banco dados } & Natureza & Unidade & \multicolumn{1}{|c|}{ Descrição detalhada } \\
\hline i Controladoria & Grau de & motivação & $\begin{array}{l}\text { Nota de 0 a 10 atribuída pelo aluno, de } \\
\text { acordo com sua autoavaliação sobre seu } \\
0 \text { a } 10\end{array}$ & $\begin{array}{l}\text { grau de motivação para cursar a } \\
\text { disciplina de Controladoria do curso, seno } \\
\text { 0=nenhuma motivação e 10=motivação } \\
\text { máxima. }\end{array}$ \\
\hline ii & Periodo_curso & Tempo de & Número de & Foi informado pelo aluno o período em \\
\hline
\end{tabular}




\begin{tabular}{|c|c|c|c|c|}
\hline & & $\begin{array}{l}\text { curso, em } \\
\text { semestres }\end{array}$ & 1 a 8 & $\begin{array}{l}\text { que ele estava no curso de Ciências } \\
\text { Contábeis analisado, cuja duração é de } 8 \\
\text { semestres ou } 4 \text { anos. A informação em } \\
\text { questão foi convertida em um número } \\
\text { inteiro referente a quantidade períodos já } \\
\text { cursados. }\end{array}$ \\
\hline iii & Idade & Idade & $\begin{array}{c}\text { Quantidade } \\
\text { de anos } \\
\end{array}$ & É a idade do respondente. \\
\hline iv & Dummy_experiência & $\begin{array}{l}\text { Existência de } \\
\text { experiência } \\
\text { profissional }\end{array}$ & $\begin{array}{l}\text { Variável } \\
\text { binária }\end{array}$ & $\begin{array}{l}\text { Foi introduzida uma variável binária em } \\
\text { que o número } 1 \text { indicava a existência de } \\
\text { experiência profissional na área contábil, } \\
\text { e, } 0 \text { indicava que o respondente não } \\
\text { possuía experiência. }\end{array}$ \\
\hline $\mathrm{v}$ & Quanto_tempo_anos & $\begin{array}{l}\text { Medida da } \\
\text { existência de } \\
\text { experiência } \\
\text { profissional }\end{array}$ & $\begin{array}{c}\text { Quantidade } \\
\text { de anos }\end{array}$ & $\begin{array}{l}\text { Se o aluno possuísse experiência na área } \\
\text { contábil, portanto, a variável anterior, } \\
\text { possuísse valor " } 1 \text { ", ele deveria informar } \\
\text { quanto tempo (em anos) ele possuía de } \\
\text { experiência profissional na área contábil. }\end{array}$ \\
\hline vi & Genero & Gênero & $\begin{array}{l}\text { Variável } \\
\text { binária }\end{array}$ & $\begin{array}{l}\text { Foi introduzida uma variável binária em } \\
\text { que } 1 \text { indicava o gênero masculino, e, } 0 \\
\text { indicava gênero feminino. }\end{array}$ \\
\hline
\end{tabular}

Fonte: elaborado com base nos dados da pesquisa.

Para a identificação de um possível relacionamento entre a variável de estudo e as possíveis variáveis explicativas consideradas nesse estudo, foi utilizada a análise de regressão linear múltipla pelo método stepwise com o auxílio do pacote estatístico para as ciências sociais ou Statistical Package for the Social Sciences (SPSS) versão 15.0.

Segundo Field (2009), a análise de regressão linear dá origem a uma modelagem explicativa do comportamento da variável dependente $\left(Y_{i}\right)$, ou variável de estudo, com base no comportamento de uma ou mais variáveis independentes $\left(X_{n}\right)$, ou explicativas, sendo que, tal modelagem assume a forma apresentada na Equação 1.

$$
\hat{Y}_{i}=\left(b_{0}+b_{1} X_{1}+b_{2} X_{2}+\ldots+b_{n} X_{n}\right)+E_{i}
$$

Na Equação 1, os termos $b_{1}$ a $b_{n}$ são denominados de coeficientes, ou betas. Esses coeficientes são encontrados a partir do comportamento das variáveis independentes $\left(X_{1}\right.$ a $\left.X_{n}\right)$, e, eles representam o efeito dessas variáveis sobre o modelo explicativo do comportamento da variável de estudo $\left(\hat{Y}_{i}\right)$. O coeficiente $b_{o}$ representa o termo constante do modelo pesquisado, sendo que, este termo pode ser suprimido da modelagem explicativa caso ele não apresente significância estatística suficiente ou quando os pressupostos do estudo assim demandarem, e, nesse caso, seria gerada uma modelagem matemática explicativa no formato da Equação 2; o termo $E_{i}$ representa o erro gerado pela diferença entre as observações reais $\left(Y_{i}\right)$ do 
comportamento da variável de estudo e as observações oriundas da aplicação da modelagem explicativa $\left(\hat{Y}_{i}\right)$.

$$
\hat{Y}_{i}=\left(b_{1} X_{1}+b_{2} X_{2+} \ldots+b_{n} X_{n}\right)+E_{i}
$$

Para validação da modelagem explicativa $\left(\hat{Y}_{i}\right)$ da motivação dos alunos que integraram a amostra dessa pesquisa foram realizadas inferências envolvendo os seguintes parâmetros estatísticos preconizados por Field (2009): coeficiente de correlação (R), cujo objetivo é avaliar a correlação da variável de estudo com as variáveis explicativas incorporadas à modelagem explicativa pesquisada; coeficiente de determinação $\left(\mathrm{R}^{2}\right)$ que tem por objetivo avaliar o poder explicativo da modelagem pesquisada; estatística " $\mathrm{f}$ ", cuja finalidade é avaliar se a combinação linear das variáveis explicativas exerce influência sobre a variável de estudo; estatística " $\mathrm{t}$ ", utilizada para avaliar se os coeficientes da modelagem matemática explicativa do comportamento da variável de estudo são significativamente diferente de zero; estatística de Dubin-Watson, que tem por objetivo diagnosticar a presença de problemas relacionados à autocorrelação dos resíduos; estatísticas VIF (variance inflation factor) e Tolerância (tolerance), cuja finalidade é verificar a existência de problemas relacionados à multicolinearidade entre duas ou mais variáveis explicativas que integrarem a modelagem pesquisada; e, teste de normalidade de Kolmogorov-Smirnov que, quando aplicado aos resíduos padronizados gerados a partir do modelo explicativo da regressão linear, permite diagnosticar a presença de problemas relacionados á heterocedasticidade.

Ao considerar que no escopo do objetivo geral desta investigação encontra-se a busca pela identificação das características pessoais dos alunos do curso de Ciências Contábeis capazes de constituir-se em alguns dos direcionadores da sua motivação para cursar a disciplina de Controladoria, optou-se pela pesquisa de uma modelagem explicativa sem termo constante, portanto, no formato já descrito nesta seção pela Equação 2. Pois, dessa forma, exclui-se a possibilidade do referido termo (constante ou intercepto) desempenhar o papel de possíveis variáveis explicativas que não foram contempladas neste estudo, permitindo-se, assim, identificar o efeito exclusivo das variáveis explicativas, identificadas com possíveis direcionadores, sobre a variável de estudo.

Ainda com relação ao escopo do objetivo geral desse estudo, vislumbra-se a possibilidade dos fatores direcionadores da motivação para aprendizagem dos alunos da modalidade de ensino presencial serem diferentes dos alunos do curso a distância, por isso, inicialmente, procedeu-se a análise de regressão linear aplicada aos alunos da modalidade presencial, e, em seguida, sua aplicação aos alunos da modalidade a distância. Isso, por sua vez, tem por objetivo idientificar duas modelagens distintas de modo a se realizar suas análises e interpretações de maneira comparativa. 
Diante do exposto, esta pesquisa pode ser caracterizada como um estudo de natureza empírica, apoiado em métodos quantitativos aplicados (FACHIN, 2001; MARTINS, 2000).

\section{ANÁLISE E DISCUSSÃO DOS RESULTADOS}

Para facilitar a análise e validação dos dados, e, consequentemente, a interpretação das evidências coletadas neste estudo, esta seção foi dividida em duas partes. A primeira aborda o processo de análise de regressão linear aplicada às respostas tanto dos alunos da modalidade presencial quanto dos alunos da modalidade a distância, e, ainda, a validação das respectivas modelagens explicativas. A segunda parte trata da análise comparativa e da interpretação dos resultados obtidos a partir dos modelos identificados com base na análise regressão.

\subsection{Análise e Validação dos Dados}

A partir da aplicação da análise de regressão linear no conjunto de dados referentes às respostas coletadas junto aos alunos do curso presencial, foram identificadas duas modelagens explicativas do grau de motivação daqueles discentes, conforme pode ser visto na Tabela 2.

Tabela 2 - Resumo dos modelos pesquisados para os alunos do curso presencial ${ }^{(\mathrm{a}, \mathrm{d})}$

\begin{tabular}{|c|c|c|c|c|c|c|}
\hline \multirow{2}{*}{$\begin{array}{l}\text { Model } \\
\text { o }\end{array}$} & \multirow{2}{*}{$\begin{array}{l}\text { Coef. de } \\
\text { correlaçãao } \\
\text { (R) }\end{array}$} & \multirow{2}{*}{$\begin{array}{c}\text { Coef. de } \\
\text { determinação } \\
\mathrm{R}^{2}\end{array}$} & \multirow{2}{*}{$\begin{array}{c}\text { Erro-padrão } \\
\text { da } \\
\text { estimativa }\end{array}$} & \multicolumn{2}{|c|}{ Estatística f } & \multirow{2}{*}{$\begin{array}{c}\text { Estatística de } \\
\text { Durbin- } \\
\text { Watson }\end{array}$} \\
\hline & & & & Valor-p & Sig. do Valor-p & \\
\hline 1 & $.942^{(b)}$ & .887 & 2.913 & 672,074 & .000 & \\
\hline 2 & $945^{(\mathrm{c})}$ & .893 & 2,848 & 354,029 & .000 & 1,691 \\
\hline \multicolumn{7}{|c|}{ a Regressão sem o termo constante } \\
\hline \multicolumn{7}{|c|}{ b Variáveis explicativas: Idade } \\
\hline \multicolumn{7}{|c|}{ c Variáveis explicativas: Idade, Quanto_tempo_anos } \\
\hline \multicolumn{7}{|c|}{ d Variável dependente: Controladoria } \\
\hline
\end{tabular}

Fonte: elaborado com base nos dados da pesquisa e nas análises realizadas no SPSS.

O primeiro modelo foi capaz de explicar $88,7 \%\left(R^{2} \times 100\right)$ das observações referentes aos alunos do curso presencial. Sendo que, nessa modelagem a única variável considerada estatisticamente significante foi a idade dos discentes, cujo valor médio foi de 24 anos, conforme já demonstrado na Tabela 1, apresentada na seção anterior. A segunda modelagem identificada foi capaz de explicar 89,3\% das observações referentes aos alunos do curso presencial e foi composta pela idade e pelo tempo de experiência profissional dos alunos na área contábil, cuja média foi de 3 anos, conforme demonstrado também na Tabela 1 apresentada na seção anterior. Assim, esse segundo modelo pode ser considerado melhor modelo analítico- 
explicativo da motivação dos alunos do curso presencial para cursar a disciplina de Controladoria.

Oportunamente, ainda segundo as informações resumidas na Tabela 2, destaca-se que a combinação linear daquelas duas variáveis explicativas (idade e tempo de experiência profissional na área contábil) exerce relevante influência sobre a variável de estudo, conforme a significância do valor parâmetro da estatística " $\mathrm{f}$ " do modelo em questão (sig. do valor-p <0,05) (FIELD, 2009). Adicionalmente, respectiva estatística de Durbin-Watson permite descartar a presença de correlação entre os resíduos gerados pelo modelo 2 e a variável de estudo, afastando-se assim a hipótese de existência de autocorrelação residual $(1<$ estatística de Durbin-Watson $<3)$ (FIELD, 2009).

Passando à aplicação da análise de regressão linear no conjunto de dados referentes às respostas dos alunos do curso da modalidade a distância, também foram identificadas duas modelagens explicativas do grau de motivação daqueles discentes em relação a disciplina de Controladoria, conforme detalhamento das informações contidas na Tabela 3.

Tabela 3 - Resumo dos modelos pesquisados para os alunos do curso a distância ${ }^{(a, d)}$

\begin{tabular}{|c|c|c|c|c|c|c|}
\hline \multirow{2}{*}{$\begin{array}{c}\text { Model } \\
\text { o }\end{array}$} & \multirow{2}{*}{$\begin{array}{l}\text { Coef. de } \\
\text { correlação } \\
(\mathrm{R})\end{array}$} & \multirow{2}{*}{$\begin{array}{c}\text { Coef. de } \\
\text { determinação } \\
\mathrm{R}^{2}\end{array}$} & \multirow{2}{*}{$\begin{array}{c}\text { Erro-padrão } \\
\text { da } \\
\text { estimativa }\end{array}$} & \multicolumn{2}{|c|}{ Estatística f } & \multirow{2}{*}{$\begin{array}{c}\text { Estatística de } \\
\text { Durbin- } \\
\text { Watson }\end{array}$} \\
\hline & & & & Valor-p & Sig. do Valor-p & \\
\hline 1 & $958^{(\mathrm{b})}$ & 917 & 2.540 & 782,893 & .000 & \\
\hline 2 & $961^{(\mathrm{c})}$ & 923 & 2,462 & 419,453 & .000 & 1,930 \\
\hline \multicolumn{7}{|c|}{ a Regressão sem o termo constante } \\
\hline \multicolumn{7}{|c|}{ b Variáveis explicativas: Idade } \\
\hline \multicolumn{7}{|c|}{ c Variáveis explicativas: Idade, Dummy_experiencia } \\
\hline
\end{tabular}

Fonte: elaborado com base nos dados da pesquisa e nas análises realizadas no SPSS.

O primeiro modelo referente à motivação dos alunos da modalidade a distância foi capaz de explicar $91,7 \%$ ( $R^{2}$ x 100) das observações. Sendo que, semelhante ao que aconteceu com os alunos da modalidade presencial, nessa modelagem a única variável considerada estatisticamente significante foi a idade daqueles alunos, cujo valor médio foi de 30 anos, conforme já demonstrado antes na Tabela 1. A segunda modelagem identificada para os discentes da modalidade a distância foi capaz de explicar $92,3 \%$ das observações e foi composta pela idade e pela existência de experiência profissional desses alunos na área contábil, diferentemente do caso dos discentes da modalidade presencial, em que, o tempo de experiência era determinante da motivação daquele grupo de discentes para cursar a disciplina de Controladoria.

Com relação à validação da modelo pesquisado para os estudantes da modalidade a distância, destaca-se que a combinação linear daquelas duas variáveis explicativas (idade e existência de experiência profissional na área contábil, 
independentemente do tempo dessa experiência) exerce significativa influência sobre a variável de estudo, conforme demonstra a significância do valor parâmetro da estatística " $\mathrm{f}$ " do modelo em questão (sig. do valor-p <0,05) (FIELD, 2009). Pode-se observar também que a respectiva estatística de Durbin-Watson permite descartar a presença de autocorrelação residual ( $1<$ estatística de Durbin-Watson <3) (FIELD, 2009).

Ao avançar nesse processo de investigação, a análise das estatísticas " $t$ ” dos coeficientes da modelagem explicativa da motivação dos alunos da modalidade presencial para cursar a disciplina de Controladoria permitiu concluir que os betas (coeficientes) gerados para as variáveis idade e tempo de experiência profissional na área contábil podem ser considerados válidos, uma vez que seus valores parâmetros apresentaram significância inferior e 0,05 (sig. do valor-p <0,05) (FIELD, 2009), conforme pode ser visto na Tabela 4.

Tabela 4 - Análise dos coeficientes dos modelos pesquisados para os alunos do curso presencial $(\mathrm{a}, \mathrm{b})$

\begin{tabular}{l|l|r|r|r|r|r}
\hline \multirow{2}{*}{ Modelo } & Coeficientes & \multicolumn{2}{c|}{ Estatística t } & \multicolumn{2}{c}{$\begin{array}{c}\text { Estatísticas de } \\
\text { Colinearidade }\end{array}$} \\
\cline { 4 - 7 } & & & Valor-p & Sig. do Valor-p & Tolerance & \multicolumn{1}{c}{ VIF } \\
\hline 1 & Idade &, 321 & 25,924 &, 000 & 1,000 & 1,000 \\
\hline 2 & Idade &, 338 & 23,679 &, 000 &, 720 & 1,389 \\
& Quanto_tempo_ano &,- 118 & $-2,229$ &, 028 &, 720 & 1,389 \\
& s & & & & & \\
\hline
\end{tabular}

a Regressão sem o termo constante

b Variável dependente: Controladoria

Fonte: elaborado com base nos dados da pesquisa e nas análises realizadas no SPSS.

Ainda segundo as informações resumidas na Tabela 4, pôde-se descartar a presença de problema relacionados à multicolinearidade, pois, as estatísticas VIF e Tolerance daqueles coeficientes apresentaram, respectivamente, valores inferiores a 5,00 e superiores a 0,20, conforme sugere Field (2009).

O teste de normalidade aplicado aos resíduos padronizados gerados a partir da modelagem explicativa da motivação dos alunos do curso presencial para cursar a disciplina de Controladoria indicou existência de distribuição normal (Asymp. Sig.: 2tailed $>0,05)$, conforme demonstrado na Tabela 5. Nesse sentido, segundo Field (2009), é possível descartar a existência de correlação entre os resíduos e as variáveis explicativas, afastando-se assim a hipótese de existência de problemas relacionados à heterocedasticidade. 
Tabela 5 - Teste de normalidade de Kolmogorov-Smirnov aplicado aos resíduos padronizados gerados a partir dos modelos pesquisados para os alunos do curso presencial

\begin{tabular}{l|l|r}
\hline \multicolumn{2}{l|}{ Freq. } & 87 \\
\hline \multirow{2}{*}{ Parâmetros de Normalidade } & Média & 0,121 \\
\cline { 2 - 3 } & Desvio-padrão & 0,987 \\
\hline \multirow{2}{*}{ Diferenças nas extremidades } & Absoluta & 0,099 \\
\cline { 2 - 3 } & Positiva & 0,089 \\
\cline { 2 - 3 } & Negativa & $-0,099$ \\
\hline Kolmogorov-Smirnov Z & 0,926 \\
\hline Asymp. Sig. (2-tailed) & 0,357 (a) \\
\hline
\end{tabular}

a Distribuição do teste é Normal.

Fonte: elaborado pelo autor com base nos dados da pesquisa e nas análises realizadas no SPSS.

Segundo as informações resumidas na Tabela 6, a análise das estatísticas " $\mathrm{t}$ " da modelagem explicativa da motivação dos alunos da modalidade a distância para cursar a disciplina de Controladoria, também, permitiu concluir que os betas (coeficientes) gerados para as variáveis idade e existência de experiência profissional na área contábil podem ser considerados válidos (sig. do valor-p <0,05) (FIELD, 2009). Adicionalmente, as estatísticas VIF e Tolerance daqueles coeficientes apresentaram, respectivamente, valores inferiores a 5,00 e superiores a 0,20, conforme determina Field (2009), descartando-se a hipótese de existência de problemas relacionados à multicolinearidade.

Tabela 6 - Análise dos coeficientes dos modelos pesquisados para os alunos do curso a distância $(\mathrm{a}, \mathrm{b})$

\begin{tabular}{l|l|r|r|r|r|r}
\hline \multicolumn{2}{c|}{ Modelo } & Coeficientes & \multicolumn{2}{c|}{ Estatística t } & \multicolumn{2}{c}{$\begin{array}{c}\text { Estatísticas de } \\
\text { Colinearidade }\end{array}$} \\
\cline { 3 - 7 } \multicolumn{2}{c|}{} & & Valor-p & Sig. do Valor-p & Tolerance & \multicolumn{1}{c}{ VIF } \\
\hline 1 & Idade &, 266 & 27,980 &, 000 & 1,000 & 1,000 \\
\hline 2 & Idade &, 245 & 19,030 &, 000 &, 513 & 1,949 \\
& Dummy_experienci & 1,372 & 2,361 &, 021 &, 513 & 1,949 \\
& a & & & & & \\
\hline
\end{tabular}

a Regressão sem o termo constante

b Variável dependente: Controladoria

Fonte: elaborado com base nos dados da pesquisa e nas análises realizadas no SPSS.

Os resíduos padronizados gerados a partir da modelagem explicativa da motivação dos alunos do curso a distância também apresentaram distribuição normal (Asymp. Sig.: 2-tailed > 0,05), conforme demonstrado na Tabela 7, o que permitiu descartar a hipótese de existência de problemas relacionados à presença de heterocedasticidade, segundo Field (2009). 
Tabela 7 - Teste de normalidade de Kolmogorov-Smirnov aplicado aos resíduos padronizados gerados a partir dos modelos pesquisados para os alunos do curso a distância

\begin{tabular}{l|l|r}
\hline \multicolumn{2}{l|}{ Freq. } & 72 \\
\hline \multirow{2}{*}{ Parâmetros de Normalidade } & Média & 0,151 \\
\cline { 2 - 3 } & Desvio-padrão & 0,981 \\
\hline \multirow{2}{*}{ Diferenças nas extremidades } & Absoluta & 0,096 \\
\cline { 2 - 3 } & Positiva & 0,055 \\
\cline { 2 - 3 } & Negativa & $-0,096$ \\
\hline Kolmogorov-Smirnov Z & 0,816 \\
\hline Asymp. Sig. (2-tailed) & $0,518^{(\text {a) }}$ \\
\hline
\end{tabular}

a Distribuição do teste é Normal.

Fonte: elaborado pelo autor com base nos dados da pesquisa e nas análises realizadas no SPSS.

\subsection{Análise Comparativa e Interpretação dos Resultados}

Diante das evidências coletadas e, ainda, considerando os testes realizados, pôde-se validar as duas modelagens explicativas identificadas mediante a aplicação da análise de regressão, ambas resumidas nas Equações 3 e 4.

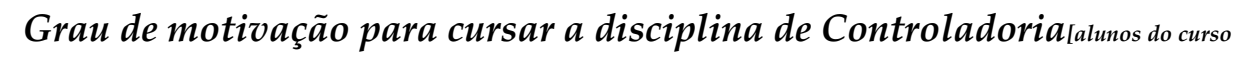
presencial] $=0,338$, (idade do aluno[em anos] $)$-0,118.(tempo de experiência profissional do aluno na área contábil [em anos] $_{\text {) }}$

Grau de motivação para cursar a disciplina de Controladoria lalunos do curso a distância] $=0,245$. (idade do aluno[em anos] $)+1,372$.(existência de experiência profissional do aluno na área contábil)

Apesar dos valores absolutos dos coeficientes daquelas duas Equações não poderem ser comparados entre si, pois, as variáveis consideradas explicativas da motivação dos alunos pesquisados possuem unidades de medidas distintas entre si, o estudo dos sinais daqueles coeficientes pode ser revelador de alguns indícios que caracterizam e distinguem o comportamento da motivação daqueles dois grupos de discentes, para cursarem a disciplina de Controladoria.

Inicialmente, observa-se o fato de que a idade dos alunos de ambos os grupos foi determinante da sua motivação para aprendizagem da disciplina de Controladoria e, uma vez que os coeficientes das duas modelagens explicativas (Equação 3 e 4) apresentaram sinais positivos, pode-se afirmar que a motivação dos alunos caminha no mesmo sentido das respectivas idades, ou seja, quanto mais elevada a idade do aluno, maior a sua motivação, e, vice-versa.

Essa evidência corrobora parcialmente os resultados do estudo de Lopes, Pinheiro e Silva (2013) e, ainda, Brown (2005), já que, apesar da idade ser considerada uma variável explicativa da motivação dos alunos analisados aqui, os fatores 
relacionados gênero e maturidade acadêmica, apontados tanto por Lopes, Pinheiro e Silva (2013) quanto por Brown (2005), não foram considerados estatisticamente significativos no presente estudo.

Ainda com relação à variável explicativa "idade", cabe observar que nos alunos do curso a distância ela apresentou um maior poder explicativo em relação aos alunos do curso presencial $\left(\mathrm{R}^{2}\right.$ do mod. 1 dos alunos do curso presencial [somente com $_{\text {s. }}$ variável explicativa=idade] $<\mathrm{R}^{2}$ do mod. 1 dos alunos curso a distância[somente com varível explicativa=idade], ou seja, $0,887<0,917)$. Essa evidência pode estar relacionada ao fato da idade média do aluno da modalidade a distância ser mais elevada que a do aluno da modalidade presencial, ou seja, 30 anos e 24 anos, respectivamente, revelando, assim, que a pouca idade dos estudantes integrantes da amostra dessa pesquisa pode ser um fator que dificulta o seu envolvimento com a própria aprendizagem. Contudo, cabe destacar que a metodologia analítica escolhida para realização desta pesquisa não permite confirmar tal suposição, o que indica a necessidade de um maior aprofundamento, que pode acontecer na continuidade deste estudo.

No que se refere à segunda variável considerada explicativa da motivação dos alunos analisados, em relação à disciplina de Controladoria, foram observadas duas características distintas para os dois grupos em estudo nessa investigação.

A primeira característica reside no fato de que o tempo de experiência profissional tem um comportamento inverso à motivação do aluno do curso presencial, pois, conforme pode ser visto na Equação 3, o coeficiente dessa variável apresentou um sinal negativo.

A segunda característica refere-se ao fato do tempo de experiência profissional na área contábil referente ao aluno do curso a distância não se caracterizar com um fator determinante da sua motivação, sendo que, no caso desse grupo de discentes (alunos da modalidade a distância), basta o aluno apresentar algum tipo de experiência profissional na área contábil para que ele se sinta mais motivado para cursar a disciplina de Controladoria, independentemente do tempo dessa experiência, conforme pode ser observando na Equação 4.

Com relação às variáveis relacionadas ao gênero, estágio/etapa no curso, conforme já dito antes, os resultados desse estudo não permitiram corroborar integralmente os achados científicos de Brown (2005), Oliveira et al (2010), e, ainda, Lopes, Pinheiro e Silva (2013).

Adicionalmente, uma vez que, nesta investigação, só foi analisada a motivação para cursar a disciplina de Controladoria, as evidências coletadas não podem ser comparadas os resultados dos trabalhos de Stipek (1998) e Jacobs e Newstead (2000) no que se refere à variação do grau de motivação relacionado a mais de uma disciplina em um mesmo curso. 


\section{CONSIDERAÇÕES FINAIS}

Ao problematizar a possibilidade de identificar dentre as características pessoais dos alunos do curso de Ciências Contábeis de uma IES privada da cidade de Uberaba-MG aquelas que pudessem constituir-se em direcionadores da sua motivação para cursar a disciplina de Controladoria, este estudo utilizou a análise de regressão linear aplicada ao conjunto de dados referentes a 87 alunos da modalidade presencial e 72 alunos da modalidade a distância, e, identificou duas modelagens explicativas daquela variável de estudo.

Inicialmente, foi observado que, tanto nos alunos do curso presencial quanto os alunos do curso a distância, a idade foi o principal determinante da motivação para cursar a disciplina de Controladoria.

Também, foi observado que fatores relacionados à experiência profissional dos discentes integrantes da amostra dessa pesquisa exercem influências distintas em relação à modalidade de ensino frequentada por cada um dos dois grupos investigados. Ou seja, no caso dos alunos do curso presencial, o tempo de experiência profissional tem um comportamento inverso à motivação, já dentre os alunos do curso a distância o tempo de experiência profissional não foi considerado estatisticamente significativo. Sendo que, nesse último grupo de alunos (curso a distância), a simples existência de algum tipo de experiência profissional na área contábil constituiu-se em um fator determinante da sua motivação para cursar a disciplina de Controladoria, independentemente do tempo dessa experiência.

Os resultados de dois dos estudos abordados na fundamentação teórica dessa pesquisa puderam ser corroborados parcialmente, ou seja, Brown (2005) e Lopes, Pinheiro e Silva (2013). Como principais limitações dessa investigação, destacam-se o fato da amostra de pesquisa ter sido formada a partir da conveniência relacionada à acessibilidade para coleta de dados, e, o fato de se buscar identificar os possíveis direcionadores da motivação relacionada a uma única disciplina no curso de Ciências Contábeis.

A despeito dessas limitações, cabe observar que, apesar das evidências coletadas nessa investigação não poderem ser generalizadas, uma vez que sua amostra foi escolhida por conveniência, o rigor analítico e metodológico empregado permitem que tais evidências possam contribuir para o debate relacionado à motivação discente para a aprendizagem em geral e, em especial, no curso de Ciências Contábeis. De forma complementar, sugere-se a continuidade desse estudo, porém, aplicada às demais disciplinas daquele curso superior.

\section{REFERÊNCIAS}

AMARAL, M. S. do; RODRIGUES, M. S. O ensino da disciplina de controladoria nos programas de pós-graduação em nível de especialização em ciências contábeis e o 
profissional controller atuante no mercado de trabalho. Enfoque Reflexão Contábil, Maringá, v. 25, n 3, p. 17-28, Set.-Dez. 2006.

BEUREN, I. M.. O papel da controladoria no processo de gestão. In: SCHMIDT, P. (Org). Controladoria: agregando valor para a empresa. Porto Alegre: Bookman/Artmed, 2002.

BROWN, N.. Meta programmes for identifying thinking preferences and their impact on accounting students' educational experience. Journal of Accounting Education. Youngstown-US, n. 23, p.232-247, 2005.

BZUNECK, J. A.. A motivação do aluno: aspectos introdutórios. In: BORUCHOVITCH, E.; BZUNECK, J. A. (Org.). A motivação do aluno: contribuições da psicologia contemporânea. 3 ed. Petrópolis: Vozes, 2004.

BZUNECK, J. A.. A motivação dos alunos em cursos superiores. In: JOLY, M. C. R. A.; SANTOS, A. A. A. dos; SISTO, F. F. (Org.). Questões do cotidiano universitário. São Paulo: Casa do Psicólogo, 2005.

COVINGTON, M. V. Self-worth theory goes to college or do our motivation theories motivate? In: McINERNEY, D. M.; VAN ETTEN, S. (Ed.) Big theories revisited. Greenwich: Information Age Publishing, 2004.

FACHIN, O.. Fundamentos da metodologia. 3. ed. São Paulo: Saraiva, 2001.

FIELD, A.. Descobrindo a estatística usando SPSS. 2. ed. Porto Alegre: Artmed, 2009.

GARRIDO, I.. Motivacion, emocion y accion educativa. In: MAYOR, L.; TORTOSA, F. (Coord.) Âmbitos de aplicacion de la psicologia motivacional. Bilbao: Desclee de Brower, 1990.

GUIMARAES, S. É. R.; BORUCHOVITCH, E.. O estilo motivacional do professor e a motivação intrínseca dos estudantes: uma perspectiva da teoria da autodeterminação. Psicologia: Reflexão e Crítica, Porto Alegre, v.17, n.2, p.143-150, 2004.

JACOBS, P. A.; NEWSTEAD, S. E. The nature and development of student motivation. British Journal of Educational Psychology, Leicester, v.70, n.2, p.243$254,2000$. 
LOPES, L. M. S.; PINHEIRO, F. M. G.; SILVA, A. D. R. da. Aspectos da motivação intrínseca e extrínseca: uma análise com discentes de Ciências Contábeis da Bahia na perspectiva da Teoria da Autodeterminação. In: CONGRESSO DA ASSONCIAÇÃO NACIONAL DOS PROGRAMAS DE PÓS-GRADUAÇÃO EM CIÊNCIAS CONTÁBEIS (ANPCONT), 7., 2013, Fortaleza. Anais... Fortaleza: ANPCONT, 2013.

MARTINS, G. de A.. Manual para elaboração de monografias e dissertações. 2. ed. São Paulo: Atlas, 2000.

MENDES, J. B.. Utilização de Jogos de Empresas no Ensino de Contabilidade - Uma experiência no curso de Ciências Contábeis da Universidade Federal de Uberlândia. Contabilidade Vista \& Revista, Belo Horizonte, v. 11, n. 3, p. 23-41, dez. 2000.

MOREIRA, M. A. Aprendizagem significativa. Brasília: Ed. da UnB, 1998.

MURPHY, P.K.; ALEXANDER, P. A. A motivated exploration of motivation terminology. Contemporary Educational Psychology, v. 25, n. 1, p.3-53, Jan./2000.

MURRAY, E. J. Motivação e emoção. Rio de Janeiro: Guanabara-Koogan, 1986.

OlIVEIRA, P. A. de et al. Motivação sob a perspectiva da Teoria da Autodeterminação: um estudo da motivação de alunos do Curso de Ciências Contábeis da Universidade Estadual de Montes Claros. In: CONGRESSO USP DE INICIAÇÃO CIENTÍFICA EM CONTABILIDADE, 7., 2010, São Paulo. Anais... São Paulo: FEA-USP, 2010.

PAJARES, F. M.; SCHUNK, D. H. Self-beliefs and school success. Self-efficacy and self-concept in academic settings. In: RIDING, R.; RAYNER, S. (Eds.). Self perception. London: Ablex Publishing, 2001.

PFROMM, S. N. Psicologia da aprendizagem e do ensino. São Paulo: EPU, 1987.

PINTRICH, P. R. A motivational science perspective on the role of student. Motivation in learning and teaching contexts. Journal of Educational Psychology, v. 95, n.4, p. 667-686, 2003.

PIRES, V. Ensino superior e neoliberalismo no Brasil: um difícil combate. Educação e Sociedade. Campinas, v.25, n.86, p.263-268, abr. 2004.

SIQUEIRA, J. R. M. de; SOLTELINHO, W.. O profissional de controladoria no mercado brasileiro: do surgimento da profissão ao dias atuais. Revista Contabilidade \& Finanças da USP, São Paulo, v.16, n. 27, p. 66-77, 2001. 
SIQUEIRA, L. G. G.; WECHSLER, S. M. Motivação para a aprendizagem escolar: possibilidades de medida. Avaliação Psicológica, Porto Alegre, v. 5, n. 1, p. 21-23, jun. 2006.

SOUZA, M. A.; LISBOA, L. P.; ROCHA, W. Práticas de contabilidade gerencial adotadas por subsidiárias brasileiras de empresas multinacionais. Revista Contabilidade \& Finanças da USP, São Paulo, v. 14, n. 32, p. 40-57,2003.

STIPEK, D. J. Motivation to learn: from theory to practice. Englewood Cliffs (NJ): Prentice Hall, 1998.

VALENTE J. A.. Formação de educadores para o uso da informática na escola. Campinas: UNICAMP, 2001. 


\section{APÊNDICE 1}

\section{Reprodução do Instrumento de Coleta Utilizado nessa Investigação}

\section{TERMO DE CONSENTIMENTO LIVRE E ESCLARECIDO}

Você está sendo convidado (a) para participar de uma pesquisa voltada para a análise motivacional dos alunos do Curso de Ciências Contábeis pertencentes a uma Instituição de Ensino Superior Privada, tanto da modalidade EAD quanto presencial, em relação à disciplina de Controladoria.

A sua participação será somente para o preenchimento do questionário, em nenhum momento você ou a sua instituição de ensino serão identificados.

Você é livre para deixar de participar da pesquisa a qualquer momento sem nenhum prejuízo ou coação.

Ao responder esse questionário e assiná-lo, você declara aceitar participar da pesquisa citada acima, voluntariamente, após ter sido devidamente esclarecido.

( de de 20

Participante da pesquisa

a) Caracterização do Respondente:

a) Período/Etapa:

b) Idade

c) Gênero (sexo):

d) Possui experiência na área contábil? informe quanto tempo? Se sua resposta for sim, (em anos).

b) Agora, por gentileza, atribua nota de 0 (zero) a 10 (dez) indicando o quanto você se sente motivado para cursar a disciplina de Controladoria do Curso de Bacharelado quem que você se encontra. Sendo 0 (zero) para totalmente desmotivado e 10 (dez) para extremamente motivado.

Não considere outros fatores além da sua motivação. Por exemplo, fatores relacionados ao desempenho do professor e à instituição de ensino que você frequenta não devem influenciar na sua resposta.

Portanto, considere apenas a sua motivação.

\begin{tabular}{|l|c|}
\hline \multicolumn{1}{|c|}{ Disciplinas } & Nota \\
\hline Controladoria & \\
\hline
\end{tabular}

